\title{
A PERMISSIBILIDADE DA APLICAÇÃO DA PRISÃO TEMPORÁRIA AO CRIME DE ASSOCIAÇÃO CRIMINOSA DO ARTIGO 288 DO CÓDIGO PENAL
}

\author{
Thaís Fernanda Nunes de Brito, Eduardo Buzetti Eustachio Bezerro \\ Universidade do Oeste Paulista - UNOESTE, curso de Direito, Presidente Prudente, SP. E-mail: tha_fern@hotmail.com
}

\section{RESUMO}

O presente artigo traz como questionamento a possibilidade deaplicar a prisão temporária (espécie de prisão cautelar processual) ao crime de associação criminosa (antigo crime de quadrilha ou bando), constantes do artigo 288 do Código Penal. A Lei 12.850/2013 trouxe, dentre outros assuntos, alterações ao referido artigo, modificando alguns de seus elementos, bem como seu nomen iuris. A controvérsia se dá em razão do rol taxativo do artigo 1 으, inciso III da Lei 7.960/89 (um dos requisitos essenciais) ainda conter a expressão "quadrilha ou bando". Diante de tais alterações, o presente artigo demonstrará se há possibilidade de invocar a prisão temporária neste tipo penal, ainda que não conste expressamente seu nomen iuris no rol dos crimes que admitem esta modalidade de prisão, sem que haja violação dos preceitos fundamentais que regem o Direito.

Palavras-chave: Direito. Prisão Temporária. Associação Criminosa. Crimes. Rol taxativo.

\section{THE PERMISSIBILITY OF PRISON TEMPORARY APPLICATION TO CRIMINAL ASSOCIATION CRIME OF THE ARTICLE 288 OF THE PENAL CODE}

\begin{abstract}
This article brings to question the possibility of applying the Temporary Prison (sort of processual precautionary prison) to crimes of Criminal Association (formerly crime of Gang or Flock), contained in article 288 of the Penal Code. The Law 12.850/2013 brought, among other things, amendments to that article by modifying some of its elements, as well as its nomem iuris. The controversy occurs because the exhaustive list of the article 1st, item III, from de Law 7.960/89 (one of the essential requirements) still contain the phrase "Gang or flock." Given these changes, this article will demonstrate if it is possible to invoke the Temporary Prison in this criminal type, though not explicitly its nomen iuris in the list of crimes which admits this prison mode, without any violation of the fundamental principles which govern the Law.
\end{abstract}

Keywords: Law. Temporary prison. Criminal Association. Crimes. Exhaustive list. 


\section{INTRODUÇÃO}

A prisão temporária é espécie de prisão cautelar aplicável aos crimes constantes do artigo 1으, inciso III da Lei 7960/89, cujo rol é taxativo, conforme majoritário entendimento doutrinário e jurisprudencial.

Com a edição da Lei $12.850 / 13$, o artigo 288 do Código Penal sofreu algumas alterações, dentre elas o nomem iuris, deixando de ser denominado como "quadrilha ou bando" e passando a ter a designação de "associação criminosa". Ocorre que o nome do dispositivo não fora alterado no rol taxativo dos crimes passíveis de prisão temporária, surgindo dúvida quanto à interpretação, questionando, pois, a possibilidade de utilizar-se dessa prisão cautelar em face dos crimes de Associação Criminosa do artigo 288, do Código Penal.

Portanto, essa abordagem se faz necessária, para o fim de aclarar a intenção do legislador com o dispositivo em questão, visando possibilitar que se atinja a finalidade da prisão temporária, ao qual é acautelar as investigações policiais sem, entretanto, violar quaisquer princípios constitucionais.

\section{METODOLOGIA}

O presente artigo desenvolveu-se a partir de levantamento de dados e informações em mídias virtuais, bem como livros, doutrinas, leis e jurisprudências pertinentes ao assunto. 0 método científico utilizado será o hipotético-dedutivo, vale dizer, partirá de uma premissa geral para uma particular, singularizada.

\section{PRISÃO TEMPORÁRIA}

Entende-se pela prisão temporária a: "Prisão cautelar de natureza processual destinada a possibilitar as investigações a respeito de crimes graves, durante o inquérito policial" (CAPEZ, 2013a, p. 165, grifo nosso). Na ótica do artigo 2o da Lei no 7.960/89, a prisão temporária “será decretada pelo Juiz, em face da representação da autoridade policial ou de requerimento do Ministério Público, e terá o prazo de 5 (cinco) dias, prorrogável por igual período em caso de extrema e comprovada necessidade" (BRASIL, 1989, p.1).

Da exegese do mencionado dispositivo legal, observa-se que o magistrado não poderá decretá-la de ofício, isto é, sem provocação dos legitimados, e que após a representação do Ministério Público ou requerimento da Autoridade Policial, terá o prazo de 24 horas para apreciar o pedido e decidir, por meio de decisão fundamentada. 
Outrossim, a Lei $\mathrm{n}$ - 7960/89, em seu artigo 1으, incisos de I a III, estampa os requisitos para a decretação da prisão temporária.

Entretanto, quanto aos requisitos dos incisos I ao III do referido artigo, a doutrina é controversa acerca de serem tais requisitos cumulativos ou alternativos, prevalecendo o entendimento de que deve ser somado ao terceiro requisito um dos dois primeiros, ou seja, a prisão temporária só será cabível em relação aos crimes elencados, quando conjugados com um dos outros dois requisitos, neste caso, sintetiza Capez (2013, p. 166, grifo nosso):

Para Damásio de Jesus e Antonio Magalhães Gomes Filho, a prisão temporária só pode ser decretada naqueles crimes apontados pela lei, desde que concorra qualquer uma das duas primeiras situações. Assim, se a medida for imprescindível para as investigações ou se o endereço ou identificação do indiciado forem incertos, caberá a prisão cautelar, e se o crime for um dos indicados por lei.

De modo a contribuir com o pensamento supra, é do entendimento de Grecco Filho (2013a, p. 309) que para a aplicação da prisão temporária, as hipóteses dos incisos do artigo 1ํ da lei no 7960/89 devem ser combinadas e não tratadas de forma autônomas.

Por fim, Jesus (2013, p. 713), exemplifica o referido entendimento:

É imprescindível que se trate de um dos crimes referidos no inc. III. O rol é taxativo e não pode ser ampliado. Não é necessário, entretanto, que as condições dos três incisos coexistam. Assim, sendo a medida imprescindível para a investigação do crime (inc. I) e havendo fundadas razões concretas da prática de um dos delitos mencionados (inc. III), não é preciso que o autor não tenha residência fixa ou que não forneça elementos de identificação pessoal (inc. II).

Faz-se saber, todavia, que a edição da Lei 12.850/2013 trouxe alterações ao crime de quadrilha ou bando (288 do Código Penal), referenciado no rol taxativo do artigo 10, inciso III, da lei de prisão temporária, levantando possível imprecisão sobre a aplicação neste caso.

\section{CRIME DE ASSOCIAÇÃO CRIMINOSA}

A lei 12.850/2013, de 2 de agosto de 2013, dentre outros assuntos, trouxe alterações ao artigo 288 do Decreto-Lei no. 2848/40 (Código Penal). Sua edição segue as diretrizes do tratado Internacional assinado e ratificado pelo Brasil na Convenção de Palermo, tal como comenta Greco Filho (2013b, p. 12):

A Convenção de Palermo é um tratado multilateral voltado à cooperação entre os Estados-partes para prevenir e coibir o crime organizado transnacional. Foi aprovada em resolução da Assembleia Geral da ONU em 15 
de novembro de 2000, adotada em Nova lorque, e, após 40 ratificações, entrou em vigor a partir de 29 de setembro de 2003. Atualmente, a Convenção foi ratificada por 147 países. O Brasil promulgou-a mediante Decreto Legislativo em 12 de março de 2004.

O artigo 288, inserido no Título IX - dos Crimes contra a Paz Pública - do Código Penal, trazia a seguinte redação:

\section{Quadrilha ou bando}

Art. 288 - Associarem-se mais de três pessoas, em quadrilha ou bando, para o fim de cometer crimes:

Pena - reclusão, de um a três anos.

Parágrafo único - A pena aplica-se em dobro, se a quadrilha ou bando é armado (grifo nosso).

Outrossim, observa-se a nova redação do mesmo dispositivo, agora alterado pela lei 12.850/2013:

\section{Associação Criminosa}

Art. 288. Associarem-se $\underline{3}$ (três) ou mais pessoas, para o fim específico de cometer crimes:

Pena - reclusão, de 1 (um) a 3 (três) anos.

Parágrafo único. A pena aumenta-se até a metade se a associação é armada ou se houver a participação de criança ou adolescente (grifo nosso).

Trata-se de delito plurissubjetivo, no qual faz-se necessária o animus de associar-se para cometer crimes, caso contrário, incide mero concurso de pessoas, tal como segue (CAPEZ, 2013b, p. 321):

Pune-se a associação (reunião) de três ou mais pessoas para o fim específico de cometer crimes, o que exclui as contravenções penais. Exige- -se um vínculo associativo entre os membros da associação criminosa, que deve ser permanente e não eventual, esporádico, do contrário poderá haver mero concurso de agentes.

Quanto às alterações, nota-se que no primeiro dispositivo fazia-se necessária a associação de mais de 3 pessoas (ou seja, maior ou igual a quatro indivíduos), e que com a alteração, bastam que 3 ou mais indivíduos se associem. No caso do caput, Cabette $(2014$, p.1) contribui ao dizer que “(...) houve 'novatio legis in pejus', já que a partir da Lei 12.850/13 (artigo 24) passa a exigir-se menos integrantes para o concurso necessário".

Vale frisar que o criem de Associação Criminosa de que trata o artigo 288 do Código Penal não se aplica ao constante no artigo 35, caput, da Lei 11343/2006 - Lei de Drogas. Neste, a associação de 2 indivíduos para o tráfico já configura a Associação. 


\section{ADMISSIBILIDADE DA PRISÃO TEMPORÁRIA EM FACE DO CRIME DE ASSOCIAÇÃO CRIMINOSA DO 288 DO CP}

Diante das modificações realizadas no artigo 288 do Código Penal, questionou-se sobre a admissibilidade da prisão temporária em razão do crime de Associação Criminosa sem a violação dos princípios que regem o direito, uma vez que apesar da mudança do dispositivo penal, o artigo 1ํ, inciso III, alínea I, da Lei 7.960/89, mantém em seu rol taxativo o crime denominado "quadrilha ou bando", o qual faz alusão ao artigo 288 da lei Penal.

Nesse diapasão, mister evocar a Carta Magna do nosso ordenamento jurídico, com o intuito de verificar seus princípios e elucidar qualquer receio de violá-los.

A Constituição Federal (BRASIL, 1988), em seu art. 5ํ, XXXIX, estabelece que "não há crime sem lei anterior que o defina, nem pena sem prévia cominação legal". A mesma norma consta (com mínimas distinções) do art. 1ํ do Código Penal Brasileiro.

O princípio da legalidade (nullum crimen, nulla poena sine praevia lege), considerado pela maioria dos doutrinadores como sendo um sinônimo do princípio da reserva legal, tem em sua essência o propósito de não punir criminalmente um fato que não esteja previamente estabelecido em lei. Ou seja, será lícita toda conduta que não tenha sido proibida.

Damásio Evangelista de Jesus (2012, p. 107) corrobora com essa afirmação ao ponderar que: "Não há crime sem que, antes de sua prática, haja uma lei descrevendo-o como fato punível. Por outro lado, a pena não pode ser aplicada sem lei anterior que a contenha. É licita, pois, qualquer conduta que não se encontre definida em lei penal incriminadora".

Há ainda quem dissinta da definição supra, e entenda o princípio da legalidade como sendo um gênero fragmentado.

Outrossim, a lei nova não retroagirá, exceto se em benefício do acusado. É o Princípio da Irretroatividade da Lei Penal (Nullum Crimen, Nulla Poena Sine Lege Praevia), um desdobramento do princípio da legalidade.

A este respeito, informa Merolli (2013, p. 238):

(...) a indicar que a lei penal só pode alcançar os fatos praticados depois do início de sua vigência, não incidindo, portanto, sobre os fatos que lhe são pretéritos. Ou seja, a lei penal - como qualquer outra espécie de lei - emite normas para o futuro; e se assim é, não pode ser aplicada a fatos praticados anteriormente ao início de sua vigência.

Enfim, não cabem dúvidas quanto à aplicação da norma, desde que expressa de maneira clara. 
TAXATIVIDADE E INTERPRETAÇÃO DA NORMA PENAL E PROCESSUAL: INTERPRETAÇÃO EXTENSIVA E USO DE ANALOGIA

Quanto ao conteúdo da norma, é sabido que esta deve ser dotada de taxatividade, em razão do princípio de mesmo nome.

Também conhecido como "garantia da lei certa" o princípio da taxatividade dispõe que "o legislador deve redigir a disposição típica do modo mais exaustivo possível" (MEROLLI, 2013, p. 262). Ou seja, proibido está o legislador de trazer normas penais imprecisas, fato, contudo, incidente no assunto em questão.

Em face da lei omissa ou equívoca, hipótese da Lei de Prisão Temporária que não foi atualizada, resta buscar meios de interpretação da norma penal, a fim de dirimir tais vícios. São meios para tal, a analogia e a interpretação extensiva da norma.

Ao recorrer à primeira, busca-se aplicar norma diversa, por semelhança, ao caso concreto não regulado por lei. Não deve ser aplicada como norma penal incriminadora - in malam partem.

Por outro lado, a interpretação extensiva traz em seu escopo a possibilidade de ampliar as palavras da lei, que têm se mostrado insuficientes. Para Capez (2013c, p. 42) "a letra escrita da lei ficou aquém de sua vontade (a lei disse menos do que queria, por isso a interpretação vai ampliar o seu significado)".

Nesse diapasão, nota-se que a hipótese da prisão temporária ao crime de Associação Criminosa não permite aplicação de analogia, haja vista haver lei que regulamente o assunto, bem como por versar sobre instituto prejudicial ao acusado.

Deve ocorrer, portanto, interpretação extensiva, visando "ampliar o sentido ou o alcance das palavras da lei, para fazê-las corresponder ao espírito da lei" (MEROLI, 2013, p. 260).

Constata-se, portanto, que a alteração do artigo 288 do Código Penal não afetou sua substância, bem como, na elaboração do artigo 1으, inciso III, I, da Lei 7960/89, o legislador buscou vincular a expressão "Quadrilha ou bando" ao disposto no artigo 288. Deste modo, a mudança do nomem iuris não obsta a utilização da Prisão Temporária. Nesse sentido exprime Cabette (2014, p. 1):

(...) a expressão "Quadrilha ou Bando" restou ligada ao dispositivo de lei, o qual não se alterou em termos de numeração e se manteve com relação ao conteúdo, chegando mesmo a ampliar-se, conforme demonstrado linhas acima. Assim sendo, houve mera alteração de "nomen juris", cuja formalidade não tem o condão de obstar o uso da Prisão Temporária ao crime de "Associação Criminosa", o qual nada mais é do que uma nova modalidade daquilo que se conhecia por "Quadrilha ou Bando" ampliada. A situação é completamente diversa da falta de previsão que acontece com o crime de organização criminosa previsto no artigo 2…, da Lei 12.850/13. 
Para fins de enriquecer este entendimento, saliento recentes julgados sob essa perspectiva:

HABEAS CORPUS. RECEPTAÇÃO QUALIFICADA, ADULTERAÇÃO DE SINAL IDENTIFICADOR DE VEÍCULO AUTOMOTOR e ASSOCIAÇÃO CRIMINOSA. Prisão temporária. Art. 10 da Lei 7960/89. Pretendida revogação. Inadmissibilidade. Fundamentação adequada do Magistrado a quo. Necessidade para a investigação criminal. Presença do fumus comissi delicti. Ausência de constrangimento ilegal. Ordem denegada.

(TJ-SP - HC: 22185330420148260000 SP 2218533-04.2014.8.26.0000, Relator: Diniz Fernando, Data de Julgamento: 16/03/2015, 2a Câmara de Direito Criminal, Data de Publicação: 18/03/2015)

HABEAS CORPUS. ROUBO, FURTO E ASSOCIAÇÃO CRIMINOSA. PRISÃO TEMPORÁRIA. DECISÃO FUNDAMENTADA. SUSPEITAS DE AUTORIA E IMPRESCINDIBILIDADE PARA AS INVESTIGAÇÕES POLICIAIS. - Não há que se falar em nulidade da prisão temporária decretada quando demonstrada sua imprescindibilidade para assegurar a eficiência da investigação criminal policial, desde que haja fundada suspeita de autoria.

(TJ-MG, Relator: Renato Martins Jacob, Data de Julgamento: 20/02/2014, Câmaras Criminais / 2a CÂMARA CRIMINAL).

Resta evidente a possibilidade de uso da prisão temporária aos crimes de associação criminosa do artigo 288 do Código Penal, desde que fiquem atendidos os requisitos do artigo 10, incisos I ou II, da Lei no. 7960/89.

\section{CONCLUSÃO}

Diante o abordado, fica evidente a possibilidade de aplicar a prisão temporária ao crime de associação criminosa, tipificado no artigo 288 do Código Penal, tendo em vista uma interpretação da norma de modo que demonstre a vontade do legislador ao editar a lei em questão. Pode-se dizer que a interpretação extensiva da norma, neste caso, em nada afeta os preceitos fundamentais do direito penal, mas traz a possibilidade de efetivar a intenção do legislador.

Uma vez demonstrados os requisitos que permeiam a Lei no 7.960/89, mais especificamente, em seu artigo 1ํ, inciso III, alínea I, concomitante com o inciso I ou II, faz-se, não só possível, mas também necessária o aproveitamento da prisão temporária ao caso do artigo 288 do diploma repressivo.

A alteração do nomem iuris de "Quadrilha ou Bando" para "Associação criminosa" em nada obsta o dispositivo supra, vez que esta última é meramente uma nova e ampliada modalidade do crime outrora conhecido. 
De resto, por razões óbvias, incumbe à autoridade judiciária dirimir quaisquer equívocos no tocante à interpretação legislativa (interpretação judicial) e à possibilidade da aplicação da prisão temporária em casos sub judice, pois não se desconhece que malgrado as partes e interesses conflitantes em uma peleja de ordem criminal, o Poder Judiciário é quem deve manter-se equidistante do apelo social e midiático, atentando-se aos valores consagrados pela República do Brasil, e à sua livre convicção fundamentada.

\section{REFERÊNCIAS}

BRASIL. Congresso Nacional. Lei da Prisão Temporária. Lei no. 7.960 de 21 de dezembro de 1989. Dispõe sobre prisão temporária. Diário Oficial da União, Brasília, DF, 22 dez. 1989. Disponível em: <http://www.planalto.gov.br/ccivil_03/leis/L7960.htm>. Acesso em: 06 ago. 2015.

BRASIL. Congresso Nacional. Lei de Drogas. Lei no. 11.343 de 23 de agosto de 2006. Institui o Sistema Nacional de Políticas Públicas sobre Drogas - Sisnad; prescreve medidas para prevenção do uso indevido, atenção e reinserção social de usuários e dependentes de drogas; estabelece normas para repressão à produção não autorizada e ao tráfico ilícito de drogas; define crimes e dá outras providências. Diário Oficial da União, Brasília, DF, 24 ago. 2006. Disponível em: <http://www.planalto.gov.br/ccivil_03/_ato2004-2006/2006/lei//11343.htm >. Acesso em: 06 ago. 2015

BRASIL. Constituição (1988). Constituição da República Federativa do Brasil. Brasília: Senado Federal, 1988.

CABETTE, Eduardo; OLIVEIRA, Monique Gonçalves Cossermelli. Organização criminosa, milícia privada e associação criminosa: prisão temporária. 2014. Disponível em: <http://eduardocabette.jusbrasil.com.br/artigos/121938026/organizacao-criminosa-miliciaprivada-e-associacao-criminosa-prisao-temporaria>. Acesso em: 6 ago. 2015.

CAPEZ, Fernando. Processo penal simplificado, 20 ed. São Paulo: Saraiva, 2013a.

CAPEZ, Fernando. Curso de direito penal, volume 3, parte especial: dos crimes contra a dignidade sexual a dos crimes contra a administração pública (arts. 213 a 359-H), 12 ed. São Paulo: saraiva, 2013b.

CAPEZ, Fernando. Col. direito simplificado - Direito penal simplificado: parte geral, 16 ed. São Paulo: Saraiva, 2013c.

GRECO FILHO, Vicente. Manual de processo penal, 10 ed. São Paulo: Saraiva, 2013a.

GRECO FILHO, Vicente. Comentários à Lei de Organização Criminosa: Lei n. 12.850/13, 1 ed. São Paulo: Saraiva, 2013b

JESUS, Damásio de. Direito Penal - Parte Geral, 34 ed. v. 1. São Paulo: Saraiva, 2012.

JESUS, Damásio de. Código de processo penal anotado, 26 ed. São Paulo: Saraiva, 2013. 
MEROLLI, Guilherme. Fundamentos críticos de direito penal: dos princípios penais de garantia, 2 ed. São Paulo: Atlas, 2013. 